Published in final edited form as:

Zou, X., Qin, C., Pereira, C. L., Tian, G., Hu, J., Seeberger, P. H., et al. (2018).

Synergistic Glycosylation as Key to the Chemical Synthesis of an Outer Core

Octasaccharide of Helicobacter pylori. Chemistry - A European Journal, 24(12), 2868-

2872. doi:10.1002/chem.201800049.

\title{
Synergistic Glycosylation as Key to the Chemical Synthesis of an Outer Core Octasaccharide of Helicobacter pylori
}

Xiaopeng Zou, Chunjun Qin, Claney L. Pereira, Guangzong Tian, Jing $\mathrm{Hu}$, Peter H. Seeberger, Jian Yin

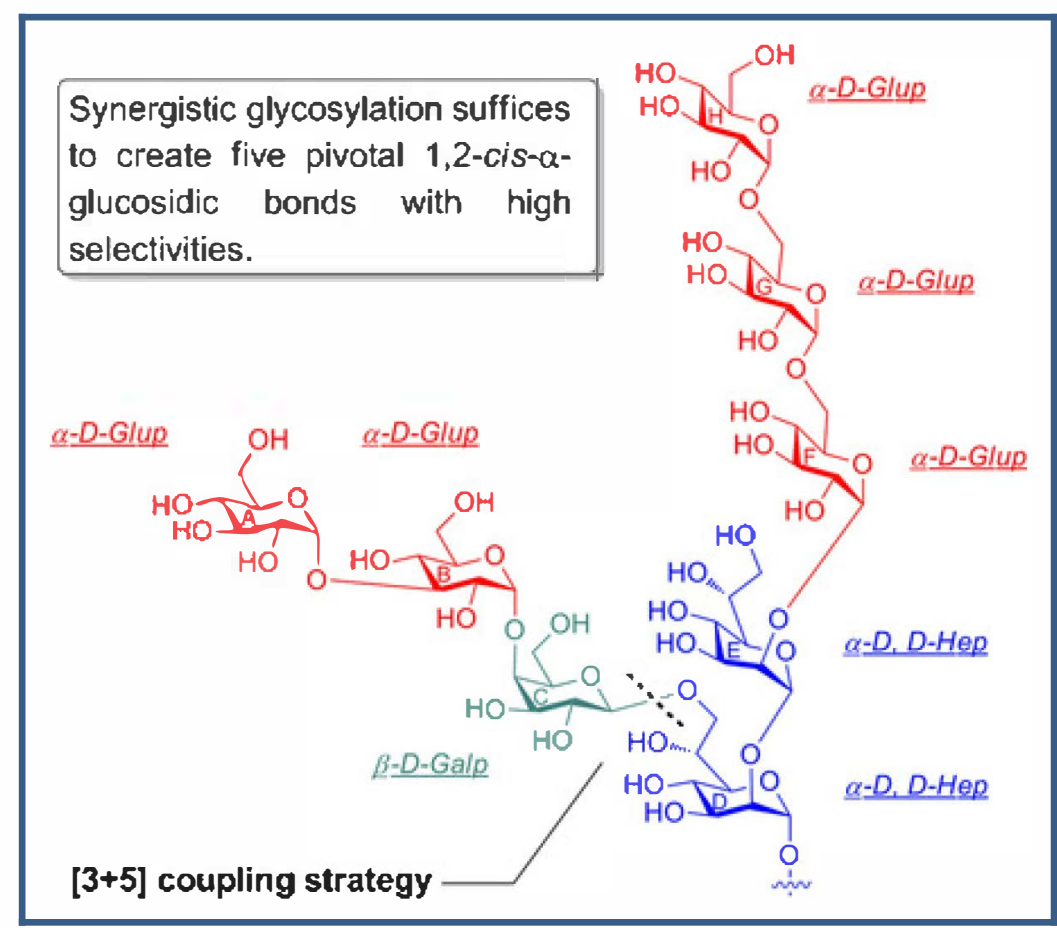

Constructing glycans of the stomach: $H$. pylori is a bacterial pathogen that infects more than half of the world's population. A synergistic glycosylation strategy was developed to construct the lipopolysaccharide of the pathogen as a first step towards developing a glycoconjugate vaccine.

This Accepted Manuscript may be shared in accordance with Wiley Terms and Conditions for SelfArchiving. 


\title{
Synergistic Glycosylation as Key to the Chemical Synthesis of an Outer Core Octasaccharide of Helicobacter pylori
}

\author{
Xiaopeng Zou ${ }^{[a, b]}$, Chunjun Qin ${ }^{[a, b]}$, Claney L. Pereira ${ }^{[b]}$, Guangzong Tian ${ }^{[a, b]}$, Jing $\mathrm{Hu}^{[a]}$, Peter $\mathrm{H}$. \\ Seeberger ${ }^{\star[b]}$, and Jian Yin ${ }^{\star[a]}$
}

Dedicated to the memory of Prof. Dr. Werner G. G. Reutter

\begin{abstract}
Helicobacter pylori, a widespread gastric bacterial pathogen that infects $90 \%$ of the population in developing countries, causes chronic gastritis, peptic ulcers and gastric cancer. Battling $H$. pylori infection is a serious challenge due to the increased resistance to antibiotics and the lack of vaccines. The lipopolysaccharide covering the $\mathrm{H}$. pylori cell-surface outer membrane is an attractive target for the development of a glycoconjugate vaccine. Here, we report a [3+5] convergent synthesis of an outer core octasaccharide of $H$. pylori employing just three orthogonally protected building blocks. A synergistic glycosylation strategy enables the creation of five pivotal 1,2-cis- $\alpha$-glucosidic bonds consist of four types of linkages using just three monomers. This strategy can be expanded to many 1,2-cis- $\alpha$-gluoside-containing oligosaccharides both in solution and on solid phase.
\end{abstract}

The bacterial pathogen Helicobacter pylori has coevolved with humans, and colonizes over half of the world's population. ${ }^{[1]}$ In contrast to other Gram-negative bacterial pathogens, $H$. pylori is able to sustain the acidic environment of the stomach and establish chronic infections. ${ }^{[2]} \mathrm{H}$. pylori infections are a major global health problem, since the pathogen causes not only chronic gastritis of asymptomatic carriers, but also leads to gastric and duodenal ulcers, and gastric malignancies. H. pylori is estimated to be responsible for $5 \%$ of all cancer cases and more than $60 \%$ of gastric cancer cases. ${ }^{[3]}$ In $1994, H$. pylori was recognized as a category I human carcinogen by the World Health Organization. ${ }^{[4]}$ To date, the treatment of $H$. pylori infections relies on various combinations of antibiotics that gradually lose effectiveness due to increased clinical resistance. ${ }^{[5]}$ No $H$. pylori vaccines exist even though various bacterial antigens, including urease, vacuolating cytotoxin $A$, cytotoxin-associated antigen, neutrophil-activating protein have been tested. ${ }^{[5 a .6]}$

Protein-saccharide conjugates induce the T-cell mediated production of antibodies to the corresponding pathogen and thereby convey immunological memory. ${ }^{[7]}$ Glycoconjugates, derived by coupling carbohydrate antigens to immunogenic protein carriers, are safe and efficacious human vaccines. ${ }^{[8]}$

[a] X. Zou, C. Qin, G. Tian, Dr. J. Hu, Prof. J. Yin Key Laboratory of Carbohydrate Chemistry and Biotechnology, Ministry of Education, School of Biotechnology, Jiangnan University, Lihu Avenue 1800, Wuxi, Jiangsu province, 214122 (P. R. China) E-mail: jianyin@jiiangnan.edu.cn

[b] X. Zou, C. Qin, Dr. C. L. Pereira, G. Tian, Prof. P. H. Seeberge Department of Biomolecular Systems,

Max Planck Institute of Colloids and Interfaces,

Am Mühlenberg 1, 14476 Potsdam (Germany)

E-mail: peter.seeberger@mpikg.mpg.de

Supporting information for this article is given via a link at the end of the document.
Lipopolysaccharide (LPS) is a main $H$. pylori cell wall component and LPS-associated serotypes have been discovered. ${ }^{[9]}$ Recently, Monteiro et al. demonstrated the potential of a LPSbased vaccine against $H$. pylori, where the conserved core undecasaccharide ${ }^{[9 b, 10]} 1$ (Figure 1) was identified as a promising antigen for the development of a glycoconjugate vaccine targeting all strains. ${ }^{[11]}$ Since extraction and purification does not provide enough pure carbohydrate antigens, synthetic carbohydrate fragments of $H$. pylori LPS will enable immunological investigations. ${ }^{[11 d, 12]}$

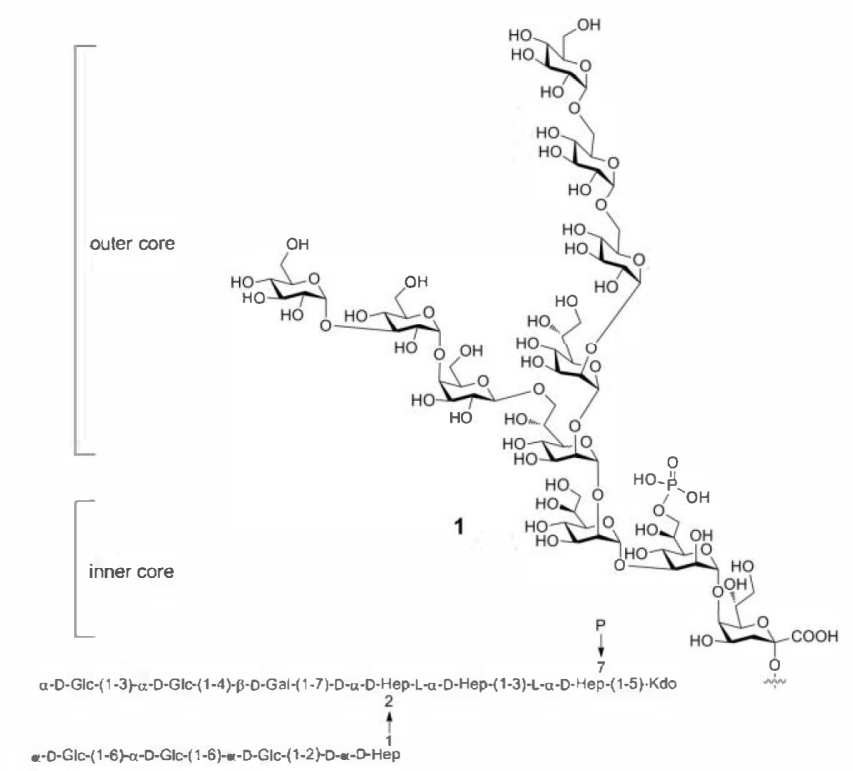

Figure 1. Structure of core undecasaccharide 1 of Helicobacter pylori.

The outer core octasaccharide portion of core undecasaccharide 1 is the key synthetic target. The retrosynthetic analysis of the outer core octasaccharide 2 bearing an amyl amine linker (Scheme 1) reveals that reliable $\alpha$ selective glycosylations are essential to install five pivotal 1,2cis- $\alpha$-glucosidic bonds. ${ }^{[13]}$ Convergent strategies can focus either on a [4+4] or a [3+5] key coupling. Therefore, three primary building blocks, glucoside 5 (Scheme 1, A, B, C, G and H), galactoside 6 (Scheme 1, F) and heptoside 7 (Scheme 1, D and $\mathrm{E})$ are required in multigram quantities. The selective formation of five 1,2-cis- $\alpha$-glucosidic bonds ( $\alpha$-D-Glu) is the most challenging aspect of the assembly of octasaccharide 2. Many oligo- and polysaccharides that contain 1,2-cis-O-glycosidic linkages are biologically important. ${ }^{[14]}$ Numerous successful methods ${ }^{[15]}$ for the installation of 1,2 -cis- $\alpha$-glycosides have been developed but a general method is still elusive. ${ }^{[16]}$ 

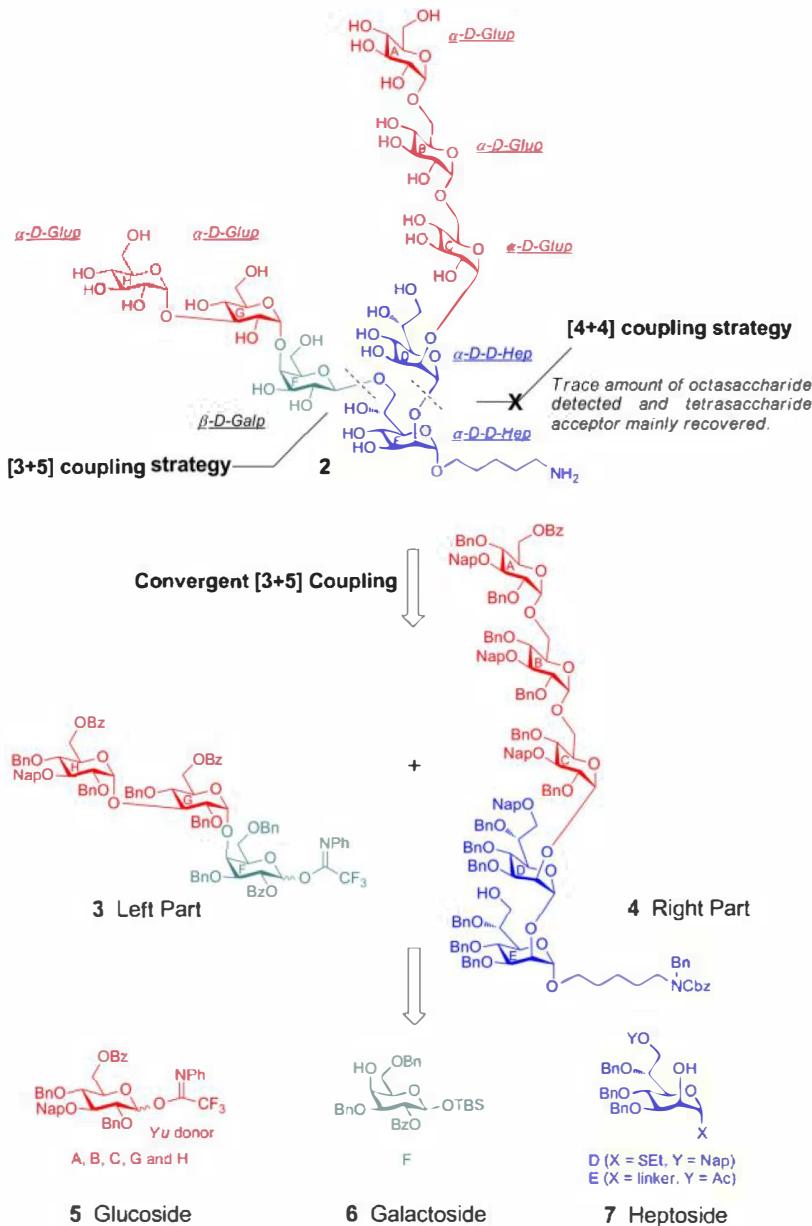

leaving groups had only little effect on the diastereoselectivity of the glycosylation. Glycosyl trichloroacetimidates (Schmidt donor $)^{[19]}$ and thioglycosides, ${ }^{[20]}$ are the most popular glycosylating agents. Recently, the $\mathrm{Yu}$ donor has evolved as an effective and alternative glycosylating agent, ${ }^{[21]}$ (3) Reaction temperature: is an important factor to select a proper glycosyl donor. While Schmidt glycosylation proceeds at low temperature, $\mathrm{Yu}$ donors are generally activated under mild condition, ${ }^{[21]}$ which well meets the required reaction temperature for Bz-capped C6 hydroxyl group to drive the remote anchimeric assistance; ${ }^{[17,22]}$ (4) Solvents system: diethyl ether $\left(\mathrm{Et}_{2} \mathrm{O}\right)$ ensures better $\alpha$ selectivity as does the additive thiophene. ${ }^{[15 c, 16]} \mathrm{A}$ combination of solvents and additive $\left(\mathrm{DCM} / \mathrm{Et}_{2} \mathrm{O} /\right.$ thiophene) was considered to improve the selectivity. Taking the four aspects, leaving group, protecting group at 6-position, as well reaction temperature and solvents laid out in detail above into account, the building blocks for the synergistic glycosylation strategy were designed (Figure 2). Next, this strategy was tested using the designated $Y u$ donor 5 for the assembly of oligosaccharides.

Orthogonally protected Yu donor $\mathbf{5}$, together with four glycosyl acceptors 7D, 8, 9 and $\mathbf{1 0}$ (synthesis details see Supporting Information) were utilized to test the formation of four different types of 1,2-cis- $\alpha$-glucosidic bonds (Scheme 2 ) present in octasaccharide 2 (Scheme 1, 8 for $1-\rightarrow 6$ bond between $A$ and $B$; 9 for $1-\rightarrow 3$ bond between $\mathrm{G}$ and $\mathrm{H} ; \mathbf{1 0}$ for $1 \rightarrow 4$ bond between $\mathrm{F}$ and $G ; 7 D$ for $1-\rightarrow 2$ bond between $C$ and $D$ ). After careful optimization of the glycosylations, the assembly of all disaccharides (Figure 5 ) involving donor 5 (1.0 equiv.) and acceptors 7D, 8, 9 and $\mathbf{1 0}$ (1.2-1.5 equiv.) were successfully promoted by using catalytic TMSOTf $(0.15$ equiv. $)$ in the presence of a solvent mixture $\left(\mathrm{DCM} / \mathrm{Et}_{2} \mathrm{O}=1 / 2\right)$ at $0{ }^{\circ} \mathrm{C}-\mathrm{RT}$. The addition of ten equivalents thiophene enhanced the $\alpha$

Scheme 1. Retrosynthetic analysis of octasaccharide 2

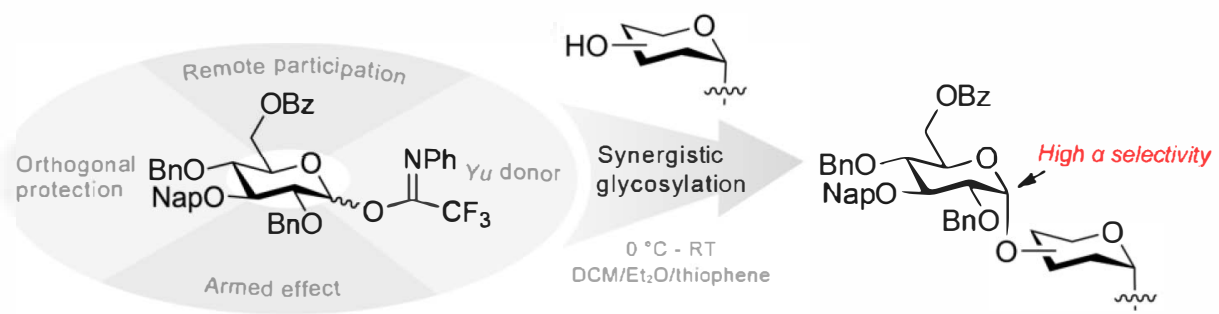

Figure 2. Synergistic glycosylation by using a versatile $Y u$ donor for high $\propto$ selectivity in the presence of $D C M / E t_{2} O /$ thiophene at $0{ }^{\circ} \mathrm{C}-\mathrm{RT}$.

Here, we report a synergistic glycosylation strategy (Figure 2), which relies on an integrated design centered on an orthogonally protected glycosyl trifluroacetimidate ( $Y u$ donor) 5. Several aspects of glycoside formation were taken into consideration: (1) Protecting groups: remote participation by placement of benzoate esters $(\mathrm{Bz})$ on the $\mathrm{C} 3$ and/or $\mathrm{C} 6$ hydroxyl groups results in higher selectivities during the construction of 1,2-cis- $\alpha$ glucosidic bonds. ${ }^{[17]}$ The C2-hydroxyl is protected with a benzyl ether $(\mathrm{Bn})$ as a non-participating group. In anticipation of chain elongation, naphthalene ether (Nap) was placed for orthogonal protection of the C3-hydroxyl; (2) Leaving group: aside from occasional $\mathrm{S}_{\mathrm{N}}-2$ like inversion transformations, most glycosylation reactions proceeded via an $S_{N}-1$ displacement mechanism. ${ }^{[16,18]}$ Accordingly, the orientation of the anomeric selectivity. ${ }^{[16,23]}$ Three disaccharides $11\left({ }^{3} J_{\mathrm{H} 1 / \mathrm{H} 2}=3.5 \mathrm{~Hz}\right), 12$ $\left({ }^{3} J_{\mathrm{H} 1 / \mathrm{H} 2}=3.6 \mathrm{~Hz}\right)$ and $14\left({ }^{3} J_{\mathrm{H} 1 / \mathrm{H} 2}=3.6 \mathrm{~Hz}\right)$ were synthesized in good yields (53-75\%) as exclusively 1,2-cis- $\alpha$-glucosidic disaccharides were obtained. The union of donor $\mathbf{5}$ and acceptor 10 (synthesis details see Supporting Information) yielded only $28 \%$ of target disaccharide $13\left({ }^{3} J_{\mathrm{H} 1 / \mathrm{H} 2}=3.5 \mathrm{~Hz}\right)$ due to the intermolecular migration of the ethylthio functional group from acceptor to donor. ${ }^{[2]}$ To avoid this undesired migration, 1-O-TBS glycoside 6 (synthesis details see Supporting Information) was employed for the synthesis, and exclusively $\alpha$-linked disaccharide $15\left({ }^{3} \mathrm{~J}_{\mathrm{H} 1 / \mathrm{H} 2}=3.8 \mathrm{~Hz}\right)$ was obtained in $72 \%$ yield According to these disaccharides models, the synergistic glycosylation strategy enabled the selective formation of four types of 1,2-cis- $\alpha$-glucosidic bonds present in octasaccharide 2. 

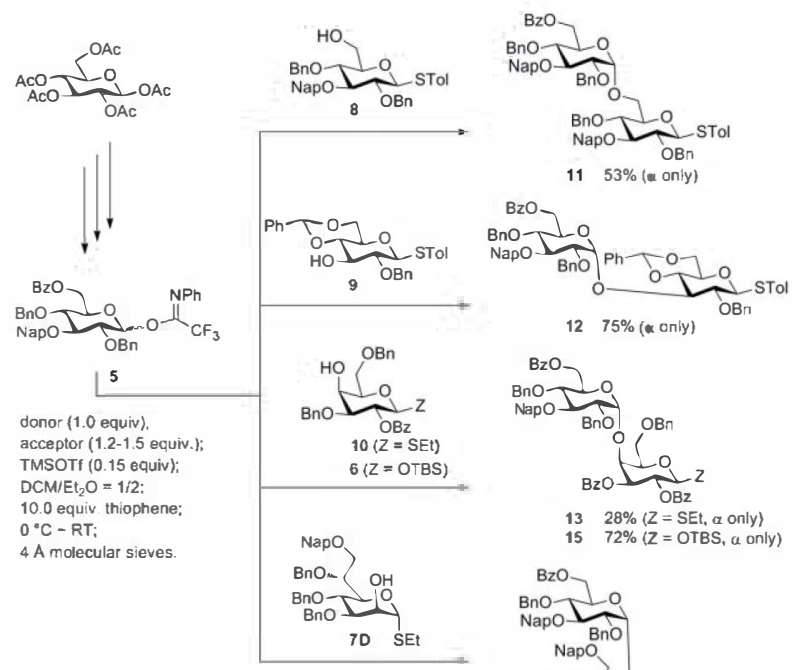

$1275 \%($ only)

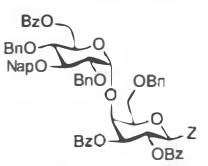

$1328 \%(Z=S E t, a$ or

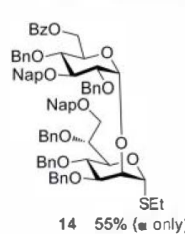

Scheme 2. Model synthesis of 1,2-cis- $\alpha$-glucosidic disaccharides 11-15 through synergistic glycosylation strategy.

The remaining primary glycosylating building block $7 \mathrm{E}$ (synthesis details see Supporting Information) was synthesized by glycosylation of an amyl amine linker with 7D. With all required glycosides 5,6 and 7 in hand, the assembly of octasaccharide 2 commenced (Scheme 1). Initially, a [4+4] convergent entry where the final coupling was tried between two heptosides 7D and 7E was evaluated. However, only traces of octasaccharide were detected while tetrasaccharide acceptor was mainly recovered (Scheme 1 ) because steric hindrance in 7E impeded the completion of the planned coupling. Therefore, the union of 3 and 4 following a [3+5] entry (Scheme 1) was selected for octasaccharide assembly because the free $\mathrm{C7}$ hydroxyl group in 7E is better accessible than the free hydroxyl group at the $\mathrm{C} 2$-postion of $7 \mathrm{E}$.

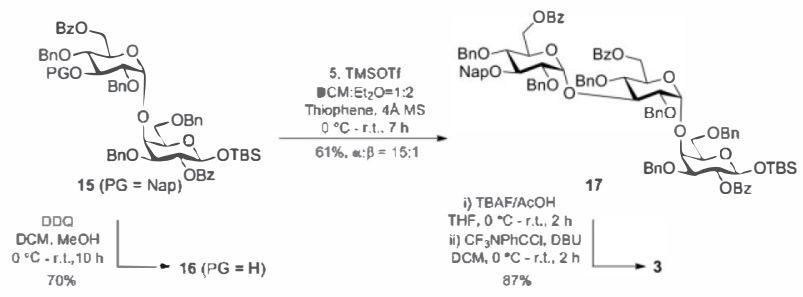

Scheme 3. Synthesis of trisaccharide fragment 3 containing two 1,2-cis- $\alpha$ -

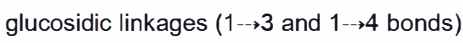

Trisaccharide 3, containing two 1,2-cis- $\alpha$-glucosidic linkages, was synthesized stepwise from the reducing to the non-reducing end (Scheme 3). The orthogonally protected $Y u$ donor $\mathbf{5}$, activated by using catalytic TMSOTf, reacted with galactosyl acceptor 6 to access disaccharide 15 in 72\% yield ( $\alpha$ exclusively) (Scheme 2). The Nap protecting group was removed smoothly with the help of 2,3-dichloro-5,6-dicyano-1,4-benzoquinone $(D D Q)^{[25]}$ to give disaccharide acceptor 16 . The second glycosylation using 5 afforded trisaccharide $17\left({ }^{3} J_{\mathrm{H} 1 / \mathrm{H} 2}=3.5 \mathrm{~Hz}\right.$,
$\left.\delta_{\mathrm{H}-1}=5.68 \mathrm{ppm}\right)$ in $61 \%$ yield $(\alpha / \beta=15 / 1)$. Subsequent transformations completed the synthesis of trisaccharide trifluroacetimidate $\mathbf{3}$ in high yield (Scheme 3 ).

The synthesis of pentasaccharide fragment 4 commenced by coupling $Y u$ donor 5 with heptosyl acceptor 7D, to form exclusively the $\alpha$-linked disaccharide 14 (Scheme 2). Subsequent removal of the temporary benzoyl protecting group was realized by sodium methoxide to afford 18 (Scheme 4). The second and third couplings were achieved employing the synergistic glycosylation strategy, to afford trisaccharide 19 $\left({ }^{3} J_{\mathrm{H} 1 / \mathrm{H} 2}=3.6 \mathrm{~Hz}, \delta_{\mathrm{H}-1}=5.00 \mathrm{ppm}\right)$ and tetrasaccharide $21\left({ }^{3} J_{\mathrm{H} 1 / \mathrm{H} 2}\right.$ $=3.6 \mathrm{~Hz}, \delta_{\mathrm{H}-1}=5.13 \mathrm{ppm}$ ) in good yields. Finally, heptosyl acceptor 7E was added to the solution of tetrasaccharide promoted by triflic acid $^{[26]}$ to give pentasaccharide 22 in $73 \%$ yield. The selective deprotection of acetyl (Ac) protecting group of 22 using $10 \%$ acetyl chloride ${ }^{[27]}$ prevented the cleavage of benzoyl protecting groups, to yield pentasaccharide acceptor 4 (Scheme 4). The two saccharide fragments 3 and 4 containing five 1,2-cis- $\alpha$-glucosidic linkages were efficiently prepared through a synergistic glycosylation strategy in good yields with very high $\alpha$ selectivities (only $\alpha$ in four cases and $\alpha / \beta=15 / 1$ in one case). Union of saccharides 3 and 4 to furnish target octasaccharide 2 was investigated next.

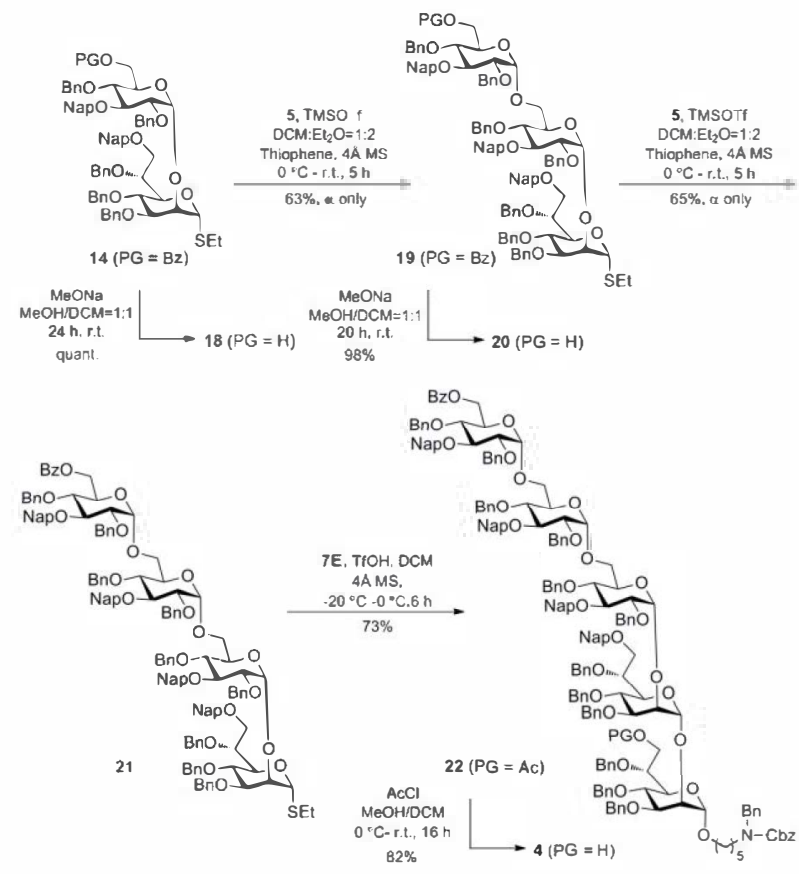

Scheme 4. Synthesis of pentasaccharide fragment 4 containing three 1,2-cis$\alpha$-glucosidic linkages (one $1 \rightarrow-2$ and two $1 \rightarrow-6$ bonds).

A convergent [3+5] synthesis strategy (Scheme 5) was used for the final coupling of trisaccharide $Y u$ donor 3 with pentasaccharide acceptor 4 catalyzed by TMSOTf to afford the fully protected octasaccharide $\mathbf{2 3}$ in good yield. Subsequent removal of all acyl protecting groups and global deprotection furnished the target octasaccharide 2 in $63 \%$ yields over two steps after final purification (Scheme 5 ). 


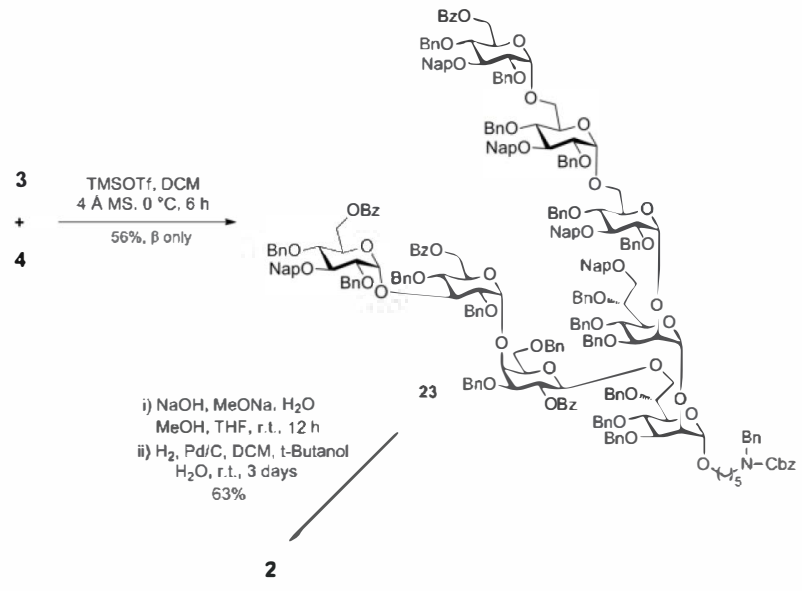

Scheme 5. Coupling of $\mathbf{3}$ and $\mathbf{4}$ to afford the target octasaccharide 2

In conclusion, the first chemical synthesis of the outer core octasaccharide of $H$. pylori is described. A synergistic glycosylation strategy based on orthogonally protected $\mathrm{Yu}$ donors enabled the selective formation of five 1,2-cis- $\alpha-$ glucosidic linkages present in octasaccharide 2 in good yields and with very high $\alpha$ selectivities. The synthetic octasaccharide 2 can be covalently bound to carrier protein via the reducing end amyl amine linker for further antigenic and immunogenic investigations, en route to the development of a glycoconjugate $H$. pylori vaccine. ${ }^{[11 \mathrm{~d}, 28]}$ The scope of this strategy can be expanded to synthesize 1,2-cis- $\alpha$-gluoside-containing oligosaccharides both in solution and on solid phase.

\section{Acknowledgements}

We are grateful for financial support from National Natural Science Foundation of China (21302068), the Max Planck Society International Partner Group Program, the High-end Foreign Experts Recruitment Program, the Thousand Talents Plan (Young Professionals), Deutscher Akademischer Austauschdienst (DAAD) and China Scholarship Council (CSC). P.H.S. thanks the Max-Planck Society for generous financial support.

\section{Conflict of interest}

The authors declare no conflict of interest.

Keywords: helicobacter pylori॰synergistic glycosylation•1,2-cis$\alpha$-glucosides•oligosaccharides•glycosylation

[1] a) J. Parsonnet, G. D. Friedman, D. P. Vandersteen, Y. Chang, J. H. Vogelman, N. Orentreich, R. K. Sibley, N. Engl. J. Med. 1991, 325, 1132 1136; b) J. Parsonnet, G. D. Friedman, D. P. Vandersteen, Y. Chang, J. H Vogelman, N. Orentreich, R. K. Sibley, R. M. Peek, M. J. Blaser, Nat. Rev Cancer 2002, 2, 28-37; c) J. C. Atherton, Annu. Rev. Pathol. Mech. Dis. 2006, 1, 63-96

[2] a) B. Marshall, J. R. Warren, Lancet 1984, 323, 1311-1315; b) D. R. Scott, E. A. Marcus, D. L. Weeks, G. Sachs, Gastroenterology 2002 123, 187-195.
[3] a) A. Axon, Scand. J. Gastroenterol. 1996, 31, 47-53; b) B. J. Marshall, H. M. Windsor, Med. Clin. N. Am. 2005, 89, 313-344; c) P. Correa, M. B Piazuelo, US gastroenterol. Hepatol. Rev. 2011, 7, 59.

[4] IARC Working Group on the Evaluation of Carcinogenic Risks to Humans Schistosomes, liver flukes and Helicobacter pylori. IARC Working Group on the Evaluation of Carcinogenic Risks to Humans. Lyon, 7-14 June 1994. IARC Monogr. Eval. Carcinog. Risks Hum. 1994, 61, 1-241.

[5] a) D. Y. Graham, Gastroenterology 1998, 115, 1272-1277; b) M. M. Gerrits, A. H. van Vliet, E. J. Kuipers, J. G. Kusters, Lancet Infect. Dis 2006, 6, 699-709; c) G. Del Giudice, P. Malfertheiner, R. Rappuoli, Expert Rev. Vaccines 2009, 8, 1037-1049.

[6] a) B. Corthésy, S. Boris, P. Isler, C. Grangette, A. Mercenier, J. Infect. Dis. 2005, 192,1441-1449; b) P. Malfertheiner, V. Schultze, B. Rosenkranz, S H. Kaufmann, T. Ulrichs, D. Novicki, F. Norelli, M. Contorni, S. Peppoloni, D. Berti, Gastroenterology 2008, 135, 787-795; c) N. R. Salama, M. L. Hartung, A. Müller, Nat. Rev. Microbiol. 2013, 11, 385-399; d) M. Zeng, X.-H. Mao, J.-X. Li, W.-D. Tong, B. Wang, Y.-J. Zhang, G. Guo, Z.-J. Zhao, L. Li, D.-L. Wu, Lancet 2015, 386, 1457-1464

[7] a) W. F. Goebel, O. T. Avery, J. Exp. Med. 1931, 54, 431-436; b) R. Schneerson, O. Barrera; A. Sutton, J. B. Robbins, J. Exp. Med. 1980, 152, 361-376; c) V. Pozsgay, Curr. Top. Med. Chem. 2008, 8, 126 140; d) F. Berti, R. Adamo, ACS Chem. Boil. 2013, 8, 1653-1663.

[8] a) C. Jones, An. Acad. Bras. Cienc. 2005, 77, 293-324; b) C. Anish, B. Schumann, C. L. Pereira, P. H. Seeberger, Chem. Biol. 2014, 21, 38-50; c) R. Adamo, Acc. Chem. Res. 2017, 50, 1270-1279.

[9] a) I. M. Simoons-Smit, B. J. Appelmelk, T. Verboom, R. Negrini, J. L. Penner, G. O. Aspinall, A. P. Moran, S. F. Fei, B. Shi, W. Rudnica, J. Clin Microbial. 1996, 34, 2196-2200; b) M. A. Monteiro in Advances in Carbohydrate Chemistry and Biochemistry, Vol 57 (Ed: D. Horton), Elsevier, Oxford, 2001, pp. 99-158.

[10] a) G. O. Aspinall, M. A. Monteiro, H. Pang, E. J. Walsh, A. P. Moran Biochemistry 1996, 35, 2489-2497; b) S. Britton, E. Papp-Szabo, J. Simala-Grant, L. Morrison, D. E. Taylor, M. A. Monteiro, Carbohydr. Res 2005, 340, 1605-1611

[11] a) C. R. Raetz, C. Whitfield, Annu. Rev. Biochem.2002, 71, 635-700; b) A Hoare, M. Bittner, J. Carter, S. Alvarez, M. Zaldivar, D. Bravo, M. A Valvano, I. Contreras, Infect. Immun. 2006, 74, 1555-1564; c) M. A. Monteiro, S. Britton, L. A. Applebee, S. Baqar, Vaccine 2011, 29, 3098 3102; d) J.A. Ferreira, L.Silva, M. A. Monteiro, M. A. Coimbra in Carbohydrate Chemistry: Chemical and Biological Approaches, Vol 37 (Ed: A. P. Rauter and T . K. Lindhorst), The Royal Society of Chemistry, Cambridge, 2012, pp. 160-193.

[12] K.-C. Chu, C.-Y. Wu, Future Med. Chem. 2012, 4, 1767-1770.

[13] P.-C. Gao, S.-Y. Zhu, H. Gao, J.-S. Yang, J. Am. Chem. Soc. 2016, 138 1684-1688.

[14] a) J. B. Robbins, C.-J. Lee, S. C. Rastogi, G. Schiffman, J. Henrichsen, Infect. Immun. 1979, 26, 1116-1122; b) S. Slovin et al, Proc. Natl. Acad. Sci. 1999, 96, 5710-5715; c) C. Zhao, M. Li, Y. Luo, W. Wu, Carbohydr Res. 2006, 341, 485-491; d) M. T. Walvoort, H. van den Elst, O. J. Plante, L. Kröck, P. H. Seeberger, H. S. Overkleeft, G. A. van der Marel, J. D. Codée, Angew. Chem. Int. Ed. 2012, 51, 4393-4396; Angew. Chem. 2012, $124,4469-4472$.

[15] a) F. J. Kronzer, C. Schuerch, Carbohydr. Res., 1974, 34, 71-78. b) R. U. Lemieux, K. B. Hendriks, R. V. Stick, K. James, J. Am. Chem. Soc., 1975, 97, 4056-4062; c) A. Ishiwata, Y. Munemura, Y. Ito, Tetrahedron 2008, 64, 92-102; d) A. Ishiwata, Y. J. Lee, Y. Ito, Org. Biomol. Chem. 2010, 8, 3596-3608; e) T. J. Boltje, J.-H. Kim, J. Park, G.-J. Boons, Nat. Chem. 2010, 2, 552-557; f) S. R. Lu, Y. H. Lai, J. H. Chen, C. Y. Liu, K. K. T Mong, Angew. Chem. Int. Ed. 2011, 50, 7315-7320; Angew. Chem. 2011 123, $7453-7458 ;$ g) H. S. Hahm, M. Hurevich, P. H. Seeberger, Nat. Commun. 2016, 7, 12482.

[16] S. S. Nigudkar, A. V.Demchenko, Chem. Sci. 2015, 6, 2687-2704.

[17] a) C. A. A. van Boeckel, T. Beetz, Recl. Trav. Chim. Pays-Bas, 1985, 104 , 171-173; b) J. Kalikanda, Z. Li, J. Org. Chem. 2011, 76, 5207-5218; c) J. Kalikanda, Z. Li, J. Org. Chem. 2011, 76, 5207-5218; d) B. S Komarova, Y. E. Tsvetkov, N. E. Nifantiev, Chem. Rec. 2016, 16, 488- 506. 
[18] a) A. F. Bochkov, G. E. Zaikov, Chemistry of the O-Glycosidic Bond: Formation and Cleavage, Pergamon Press: New York, 1979, pp.5-79; b) A. V. Demchenko, Synlett. 2003, 2003, 1225-1240; b) T. Fang, Y. Gu, W. Huang, G.-J. Boons, J. Am. Chem. Soc. 2016, 138, 3002-3011.

[19] a) R. R. Schmidt, J. Michel, Angew. Chem. Int. Ed. 1980, 19, 731-732; Angew. Chem. 1980, 92, 763-744; b) P. Peng, R. R. Schmidt, Accounts Chem. Res. 2017, 50, 1171-1183.

[20] a) R. M. Williams, A. O. Stewart, Tetrahedron Lett.1983, 24, 2715-2718 b) G. Lian, X. Zhang, B. Yu, Carbohydr. Res. 2015, 403, 13-22

[21] a) B. Yu, H. Tao, Tetrahedron Lett. 2001, 42, 2405-2407; b) B. Yu, J. Sun X. Yang, Accounts Chem. Res. 2012, 45, 1227-1236.

[22] Y. P. Cheng, H. T. Chen, C. C. Lin, Tetrahedron Lett. 2002, 43, 7721 7723.

[23] a) J. Park, S. Kawatkar, J. H. Kim, G. J. Boons, Org. Lett. 2007, 9,1959 1962; b) Y. H. Tsai, S. Götze, I. Vilotijevic, M. Grube, D. V. Silva, P. H. Seeberger, Chem. Sci. 2013, 4, 468-481.

[24] a) F. Belot, J. C. Jacquinet, Carbohydr.Res. 1996, 290, 79-86; b) A-R. de Jong, B. Hagen, V. van der Ark, H. S. Overkleeft, J. D. Codée, G. A. Van der Marel, J. Org. Chem. 2011, 77, 108-125.

[25] a) Y. Oikawa, T. Yoshioka, O. Yonemitsu, Tetrahedron Letters 1982, 23, 885-888; b)R. Pragani, P. H. Seeberger, J. Am. Chem. Soc. 2010, 133, 102-107.

[26] a) G. H. Vwneman, S. H. van Leeuwen; J. H. van Boom, Tetrahedron Lett. 1990, 31,1331-1334; b) E. Danieli, L. Lay, D. Proietti, F. Berti, P. Costantino, R. Adamo, Org. Lett. 2010, 13, 378-381; c) B. Schumann, S G. Parameswarappa, M. P. Lisboa, N. Kottari, F. Guidetti, C. L. Pereira, P. H. Seeberger, Angew. Chem. Int. Ed. 2016, 55, 14431-14434. Angew. Chem. 2016, 128, 14644-14648.

[27] a) N. E. Byramova, M. V. Ovchinnikov, L. V. Backinowsky, K. Kochetkov, Carbohydr. Res. 1983, 124, C8; b) Y. Yang, C. E. Martin, P. H.Seeberger Chem. Sci. 2012, 3, 896-899.

[28] a) R. Adamo, A. Nilo, B. Castagner, O. Boutureira, F. Berti, G. J. Bernardes, Chem. Sci. 2013, 4, 2995-3008; b) L. Kong, B. Vijayakrishnan, M. Kowarik, J. Park, A. N. Zakharova, L. Neiwert, A. Faridmoayer, B. G. Davis, Nat. Chem. 2016, 8, 242-249. 